\title{
PEMODELAN SEBARAN BOD DI SUNGAI KAPUAS KECIL BAGIAN HILIR MENGGUNAKAN WASP
}

\author{
Rizki Purnaini* \\ Ilmu Lingkungan Sekolah Pascasarjana \\ Universitas Gadjah Mada \\ Sudarmadji \\ Departemen Geografi Lingkungan \\ Fakultas Geografi Universitas Gadjah Mada \\ Suryo Purwono \\ Departemen Teknik Kimia \\ Fakultas Teknik Universitas Gadjah Mada \\ Submitted: 20-04-2018; Revised: 26-11-2018; Accepted: 29-11-2018
}

\begin{abstract}
The Kapuas Kecil River must be maintained for its water quality so that it can still be utilized in accordance with its designation. The purpose of this study is to predict water quality changes due to incoming waste from various sources of pollutants to the concentration of BOD in Kapuas Kecil River using WASP model as an effort to water quality monitoring and water pollution control.The study area to be simulated is Kapuas Kecil River passing through Pontianak City over $\pm 22 \mathrm{~km}$ from upstream to downstream (estuary) that divided into 42 segments. Water quality data were collected from several monitoring station locations in Kapuas Kecil River downstream, Landak River, effluent trenches located within the administrative area of Pontianak City, as well as secondary data on industrial effluents located along the study area. Water sampling method refers to the SNI 03-7026-2004, sampling was done once at each sample point with variations of the rainy and dry season, and at high and low tide conditions. Hydrometry data and river discharge can be obtained from primary and secondary data.The results showed that domestic and non-domestic of urban discharges that entering the river is very dominant influence on the water quality of the river. BOD concentration in rivers during the dry season is higher than rainy season both in high and low tide conditions. The simulation results of spatial distribution with all scenarios show that the accumulation of BOD pollution load begins after a distance of $5 \mathrm{~km}$ from the upstream boundary and then a significant increase in concentration occur at segment 27 with loads originating from the Landak River and Pekong Trench. The BOD concentration then tends to fluctuate to a distance of $5 \mathrm{~km}$ before heading downstream, and after that it continues to decline towards the downstream.
\end{abstract}

Keywords: BOD; Kapuas Kecil River; Water Quality; WASP Model.

${ }^{*}$ Corresponding author: rizkipurnaini@yahoo.co.id

Copyright@2019 THE AUTHOR(S). This article is distributed under a Creative Commons Attribution-Share Alike 4.0 International license. Jurnal Teknosains is published by the Graduate School of Universitas Gadjah Mada. 


\begin{abstract}
ABSTRAK
Sungai Kapuas Kecil harus dipertahankan kualitas airnya agar tetap dapat dimanfaatkan sesuai dengan peruntukannya. Tujuan penelitian ini adalah untuk memprediksi perubahan kualitas air akibat buangan yang masuk dari berbagai sumber pencemar terhadap konsentrasi BOD di Sungai Kapuas kecil menggunakan model WASP sebagai upaya pemantauan terhadap kualitas air dan pengendalian pencemaran air. Wilayah studi yang akan disimulasikan dengan pemodelan hanya dibatasi pada Sungai Kapuas Kecil bagian hilir yang melewati Kota Pontianak sepanjang $\pm 22 \mathrm{Km}$ dari hulu sungai ke arah hilir (muara) yang dibagi menjadi 42 segmen. Data kualitas air dikumpulkan dari beberapa lokasi stasiun pemantauan di sungai Kapuas Kecil bagian hilir, Sungai Landak, effluent parit yang berada di dalam wilayah administrasi Kota Pontianak, serta data sekunder effluent industri yang berada di sepanjang daerah penelitian. Metode pengambilan sampel air mengacu pada SNI 03-7026-2004, pengambilan sampel dilakukan satu kali di setiap titik sampel dengan variasi waktu musim hujan dan musim kemarau serta kondisi pasang dan surut. Data hidrometri dan debit sungai di dapat dari data primer dan data sekunder. Hasil penelitian menunjukkan bahwa buangan domestik dan non-domestik perkotaan yang masuk ke sungai sangat dominan mempengaruhi kualitas air sungai. Konsentrasi BOD di sungai pada saat musim kemarau lebih tinggi dibandingkan pada saat musim hujan baik pada kondsi pasang maupun surut. Hasil simulasi distribusi spasial dengan semua skenario yang dijalankan menunjukkan bahwa akumulasi beban pencemaran BOD mulai terjadi setelah jarak 5 $\mathrm{km}$ dari hulu boundaries dan kemudian terjadi lonjakan konsentrasi yang signifikan dengan adanya load di segmen 27 yang berasal dari Sungai Landak dan Parit Pekong. Konsentrasi BOD selanjutnya cenderung berfluktuasi dan kembali meningkat sampai pada jarak $5 \mathrm{~km}$ sebelum menuju hilir, dan setelah itu terus menurun sampai ke hilir.
\end{abstract}

Kata Kunci: BOD; Kualitas Air; Model WASP; Sungai Kapuas Kecil.

\section{PENGANTAR}

Sungai Kapuas Kecil merupakan anak Sungai Kapuas di bagian hilir yang alirannya dari hulu ke hilir melewati 3 (tiga) wilayah administrasi, yaitu: Kabupaten Kubu Raya,
Kota Pontianak, dan Kabubaten Mempawah. Sungai Kapuas Kecil membelah dan melewati Kota Pontianak sebelum menuju muara ke Selat Karimata. Sungai Kapuas Kecil memiliki percabangan dengan Sungai Landak yang juga membelah Kota Pontianak bagian utara. Kota Pontianak banyak memiliki sungai kecil/parit yang berfungsi sebagai drainase dan sekaligus sebagai penampungan limbah domestik dimana semua sungai kecil/parit ini akhirnya bermuara ke sungai Kapuas Kecil, sehingga Sungai Kapuas Kecil merupakan muara Sungai Landak dan sebagai penampungan akhir berbagai jenis limbah dari aktivitas masyarakat Kota Pontianak. Sumber utama pencemar yang masuk ke Sungai Kapuas kecil bagian hilir berasal dari limbah domestik pemukiman dan aktivitas perdagangan dan jasa, limbah industri besar dan kecil serta limpasan perkotaan. Beban pencemaran BOD di Kota Pontianak didominasi oleh limbah domestik yaitu $94,38 \%$ atau $12.092,32 \mathrm{~kg} /$ hari, dimana sumber pencemar lainnya tidak memberikan kontribusi yang signifikan (KLHK, 2016).

Sungai Kapuas Kecil dipengaruhi oleh pasang surut air laut, ketika kondisi pasang tertinggi kenaikan muka air laut bisa mencapai hingga daerah percabangan Sungai Kapuas dan Sungai Kapuas Kecil. Berdasarkan data yang didapat dari DISHIDROS Angkatan Laut Ancol Jakarta tahun 2014, tipe pasang surut di Sungai Kapuas Kecil adalah tipe campuran dominan ganda (mixed tide prevailing semidiurnal), dalam satu hari terjadi dua kali air pasang dan dua kali air surut, tetapi tinggi dan periodenya berbeda.

Sungai Kapuas Kecil memiliki fungsi yang strategis bagi masyarakat di kabupaten/kota yang dilewatinya karena merupakan sumber air baku untuk pengolahan air minum bagi PDAM, air baku untuk kegiatan industri, budidaya perikanan, penunjang sarana transportasi, rekreasi, bahkan sebagian masyarakat yang tidak berlangganan PDAM masih memanfaatkan air sungai secara langsung untuk keperluan MCK. Hasil penelitian yang dilaporkan oleh Pusat Pengelolaan Ekoregion Kalimantan, Kementrian Lingkungan Hidup tahun 2011, parameter BOD dan COD air sungai Kapuas sudah melampaui kelas yang diperuntukkan, sebanyak 70\% 
penyumbang pencemaran Sungai Kapuas adalah limbah domestik.

Sebagai sumber utama air baku bagi PDAM dan peruntukan lainnya, Sungai Kapuas Kecil harus dipertahankan kualitas airnya agar tetap dapat dimanfaatkan sesuai dengan peruntukannya, karena tujuan penelitian ini adalah untuk memprediksi perubahan kualitas air akibat buangan yang masuk dari berbagai sumber pencemar terhadap konsentrasi BOD di Sungai Kapuas kecil menggunakan model WASP sebagai upaya pemantauan terhadap kualitas air dan pengendalian pencemaran air.

Menurut Ji (2012), alasan utama untuk melakukan pemodelan sungai adalah Pertama, untuk lebih memahami proses fisika, kimia, dan biologi. Kedua, untuk mengembangkan model yang mampu mewakili realita sungai, sehingga model dapat digunakan untuk mendukung pengelolaan kualitas air dan pengambilan keputusan.

Model WASP mengkaji setiap bagian kualitas air berdasarkan input spasial dan temporal dari titik awal hingga ke titik akhir perpindahan, berdasarkan prinsip konservasi massa dalam ruang dan waktu (Ambrose dan Wool, 2009).

Persamaan keseimbangan massa untuk konstituen terlarut dalam badan air harus memperhitungkan semua material yang masuk dan keluar melalui beban masukan langsung dan difusi; adveksi dan dispersi; serta transformasi fisik, kimia, dan biologi (US EPA, 2009). Umumnya, keseimbangan massa untuk model satu dimensi dapat dihitung dengan mengikuti persamaan (Ambrose and Wool, 2009) :

$\frac{\partial(A C)}{\partial t}=\frac{\partial}{\partial x}\left(-U_{x} A C+E_{x} A \frac{\partial C}{\partial x}\right)+A\left(S_{L}+S_{B}\right)+A S_{K}$

dimana :

$\begin{aligned} \mathrm{C}= & \text { konsentrasi bahan pencemar } \\ & \left(\mathrm{mg} / \mathrm{L} \text { atau } \mathrm{g} / \mathrm{m}^{3}\right) \\ \mathrm{t}= & \text { waktu (hari) } \\ \mathrm{U}_{\mathrm{x}}= & \text { kecepatan adveksi longitudinal } \\ & (\mathrm{m} / \text { hari }) \\ \mathrm{A}= & \text { luas permukaan aliran }\left(\mathrm{m}^{2}\right) \\ \mathrm{E}_{\mathrm{x}}= & \text { koefisien dispersi longitudinal } \\ & \left(\mathrm{m}^{2} / \text { hari }\right) \\ \mathrm{x} \quad= & \text { jarak sepanjang aliran }(\mathrm{m})\end{aligned}$

$\mathrm{S}_{\mathrm{L}} \quad=$ laju beban pencemar eksternal $(\mathrm{g} /$ $\mathrm{m}^{3}$-hari)

$\mathrm{S}_{\mathrm{K}} \quad=$ laju transformasi kinetik $\left(\mathrm{g} / \mathrm{m}^{3}\right.$ hari)

$\mathrm{S}_{\mathrm{B}} \quad=$ laju beban batasan $\left(\mathrm{g} / \mathrm{m}^{3}\right.$-hari $)$

Model WASP telah digunakan untuk berbagai kajian di antaranya Kuo, $d k k$ (2000) menggunakan model WASP5 untuk simulasi distribusi konsentrasi BOD dan DO di ChiShui River, Taiwan Selatan. Kalibrasi model menunjukkan hasil yang baik dan mampu memprediksi kualitas air di bagian hilir. Liang, dkk (2013) menggunakan WASP6 untuk memprediksi distribusi nutrisi di muara, hasil penelitian ini ditemukan bahwa model memberikan pendekatan yang baik dari proses adsorpsi / desorpsi atas berbagai konsentrasi nitrogen dan fosfor dalam muara alami. Lai, dkk (2013) menggunakan WASP untuk memodelkan kualitas air paramter BOD, $\mathrm{DO}, \mathrm{NH}_{3}-\mathrm{N}$ dan padatan tersuspensi, di mana hasil simulasi dihubungkan dengan nilai River Pollution Index (RPI) untuk menentukan status kualitas air di Sungai Kaoping, Taiwan. Model WASP juga mampu mengatasi keterbatasan metode neraca massa dalam penetapan daya tampung pencemaran di Sungai Ciujung, pada penelitian ini model WASP digunakan untuk menentukan strategi pengendalian pencemaran dengan mensimulasikan debit sungai minimum dan maksimum serta berbagai reduksi beban pencemaran (Hindriani $d k k, 2013$ ).

\section{Metode}

Wilayah studi yang akan disimulasikan dengan pemodelan hanya dibatasi pada Sungai Kapuas Kecil bagian hilir yang melewati Kota Pontianak sepanjang $\pm 22 \mathrm{~km}$ dari hulu sungai ke arah hilir (muara). Pemodelan kualitas air menggunakan model numerik terkomputerisasi WASP 7.5, yang merupakan versi terbaru yang dikembangkan oleh USEPA. WASP (Water Quality Analysis Simulation Program) digunakan untuk mensimulasikan sebaran BOD di Sungai Kapuas Kecil pada musim kemarau dan hujan saat kondisi pasang dan surut.

Data kualitas air dikumpulkan dari beberapa lokasi stasiun pemantauan, yaitu 7 


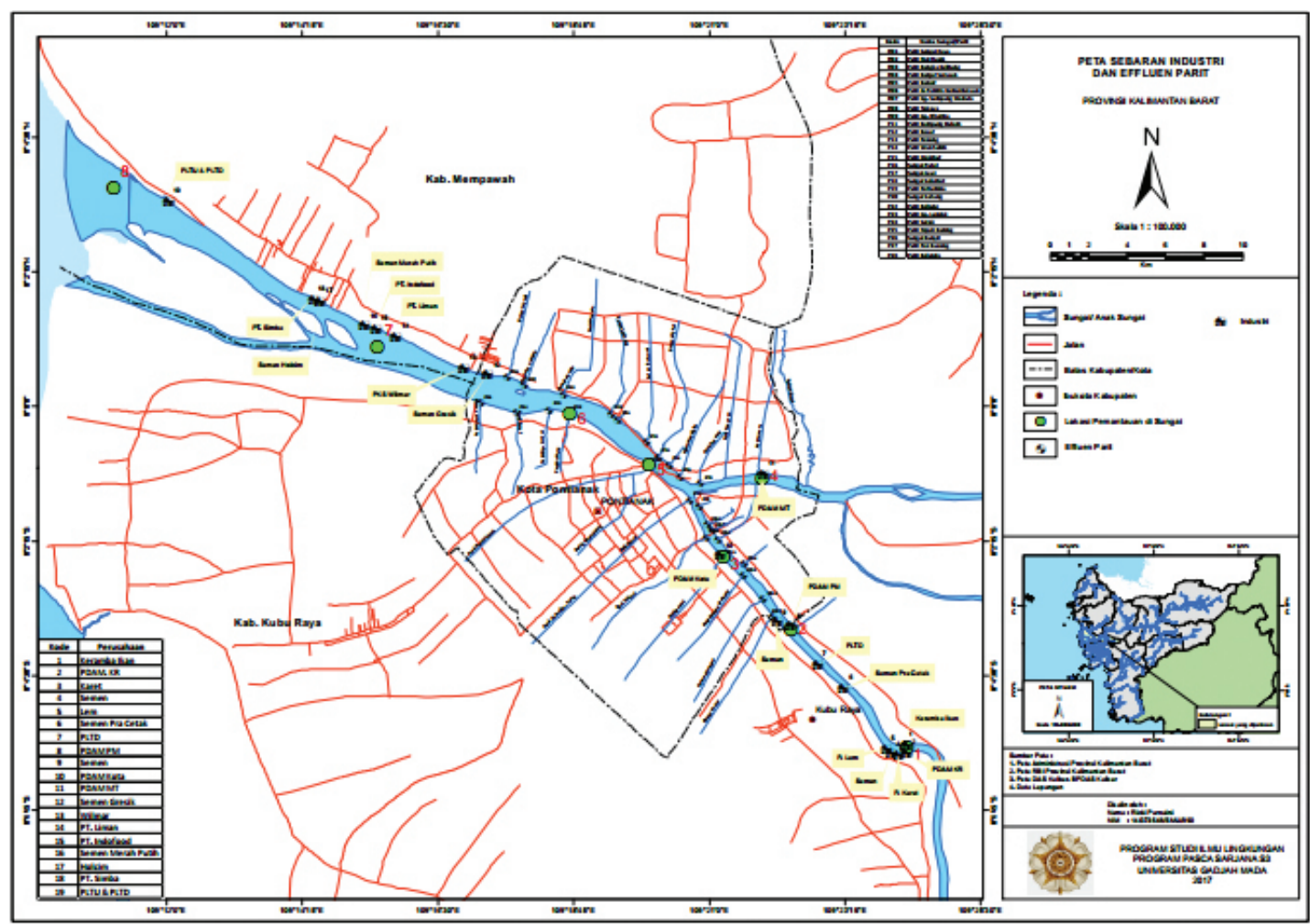

Gambar 1.

Peta Lokasi Pengambilan Sampel Air Di Lokasi Penelitian

titik di sungai Kapuas Kecil bagian hilir, 1 titik di Sungai Landak, dan 25 titik di effluent parit yang berada di dalam wilayah administrasi Kota Pontianak. Metode pengambilan sampel air mengacu pada SNI 03-7026-2004. Jenis sampel untuk pengambilan sampel di stasiun pemantauan di sungai adalah integrated sample yaitu sampel gabungan yang diambil secara terpisah dari beberapa tempat pada waktu tertentu, sedangkan untuk pengambilan sampel di effluent parit adalah grab sample yaitu pengambilan sampel sesaat di titik-titik tertentu dengan waktu pengambilan satu kali di setiap titik sampel. Pengambilan sampel air dan pengukuran kecepatan aliran dilakukan secara simultan pada masing-masing stasiun pemantau dan effluent parit dengan variasi waktu musim hujan dan musim kemarau serta kondisi pasang dan surut. Data effluent industri yang berada di sepanjang sungai daerah penelitian merupakan data sekunder yang didapatkan dari dinas terkait. Data hidrometri dan debit sungai di dapat dari data sekunder dan data primer hasil pengolahan data lapangan. Peta Lokasi pengambilan sampel air dapat dilihat pada Gambar 1.

Tahapan pemodelan kualitas air menggunakan model WASP 7.5 yaitu: segmentasi ruas sungai; pengolahan data; input data; kalibrasi model; dan pengembangan simulasi. Parameter yang dimasukkan ke dalam model adalah data hidrolika segmen, beban pencemaran (load), debit sungai (flows), dan konsentrasi parameter kualitas air di hulu dan hilir segmen (boundaries).

Beban pencemar di lokasi penelitian diasumsikan hanya dari sumber pencemar tertentu (point source) yang berasal dari effluent parit dan industri di sepanjang aliran sungai. Beban pencemaran yang berasal dari limbah domestik dari pemukimam penduduk dan aktivitas perkotaan diasumsikan sebagai beban pencemar yang masuk ke effluent parit dan selanjutnya menjadi beban pencemaran (load) yang masuk ke Sungai Kapuas Kecil.

Analisa perhitungan beban pencemaran yang dimasukkan ke dalam model dilakukan dengan memperkirakan beban pencemaran 
BOD yang bersumber dari effluent parit/ saluran drainase/ anak sungai dan industri. Untuk menghitung beban pencemaran BOD dari sumber pencemar effluent parit dan anak sungai, digunakan persamaan:

BOD sungai $(\mathrm{kg} / \mathrm{hari})=\mathrm{Q} \times \mathrm{C}_{\mathrm{BOD}} \times 86,4$

Dimana:

$\mathrm{Q}=$ Debit sungai $\left(\mathrm{m}^{3} /\right.$ detik $)$

$\mathrm{C}_{\mathrm{BOD}}=$ Konsentrasi BOD $(\mathrm{mg} / \mathrm{l})$

Sedangkan untuk menghitung beban pencemaran industri digunakan persamaan :

BOD Industri $(\mathrm{kg} /$ hari $)=$

$\left(\mathrm{C}_{\mathrm{BOD}} \times \mathrm{Q} \times\right.$ kapasitas produksi $\times$

OpHrs)/1000

dimana :

$\mathrm{C}_{\mathrm{BOD}}=$ konsentrasi $\mathrm{BOD}$ dalam buangan air limbah (mg/l)

$\mathrm{Q}=$ Debit buangan air limbah $\left(\mathrm{m}^{3} /\right.$ hari $)$.

Kapasitas produksi $=$ kapasitas produksi $\mathrm{CPO}$ (ton/jam)

OpHrs $=$ Jumlah jam operasional per hari (jam/hari)
Kalibrasi model dilakukan dengan tujuan untuk memperoleh hasil yang sesuai dengan kondisi kualitas air badan sungai Kalibrasi model Sungai Kapuas Kecil dilakukan pada debit rata-rata Sungai Kapuas yaitu $1.200 \mathrm{~m}^{3}$ / detik saat pasang, $1.234 \mathrm{~m}^{3} /$ detik saat surut, dan kondisi beban pencemaran eksisting. Model yang telah dikalibrasi dapat digunakan untuk pengembangan berbagai variasi skenario simulasi.

\section{HASIL DAN PEMBAHASAN}

Sistem yang dimodelkan pada penelitian ini adalah Sungai Kapuas Kecil bagian hilir, mulai dari lokasi intake PDAM Kubu Raya sebagi batas hulunya dan mulut sungai (muara) sebagai batas hilirnya dengan panjang \pm 22 $\mathrm{km}$ yang dibagi menjadi 42 segmen, dengan panjang segmen bervariasi antara $144-1.564$ $\mathrm{m}$. Pembagian segmen berdasarkan pada lokasi sumber pencemar dan titik pemantauan kualitas air. Segmentasi Sungai Kapuas Kecil bagian hilir untuk kepentingan pemodelan dapat dilihat pada Gambar 2, sedangkan hasil perhitungan beban pencemaran pada masingmasing segmen diuraikan pada Tabel 1.

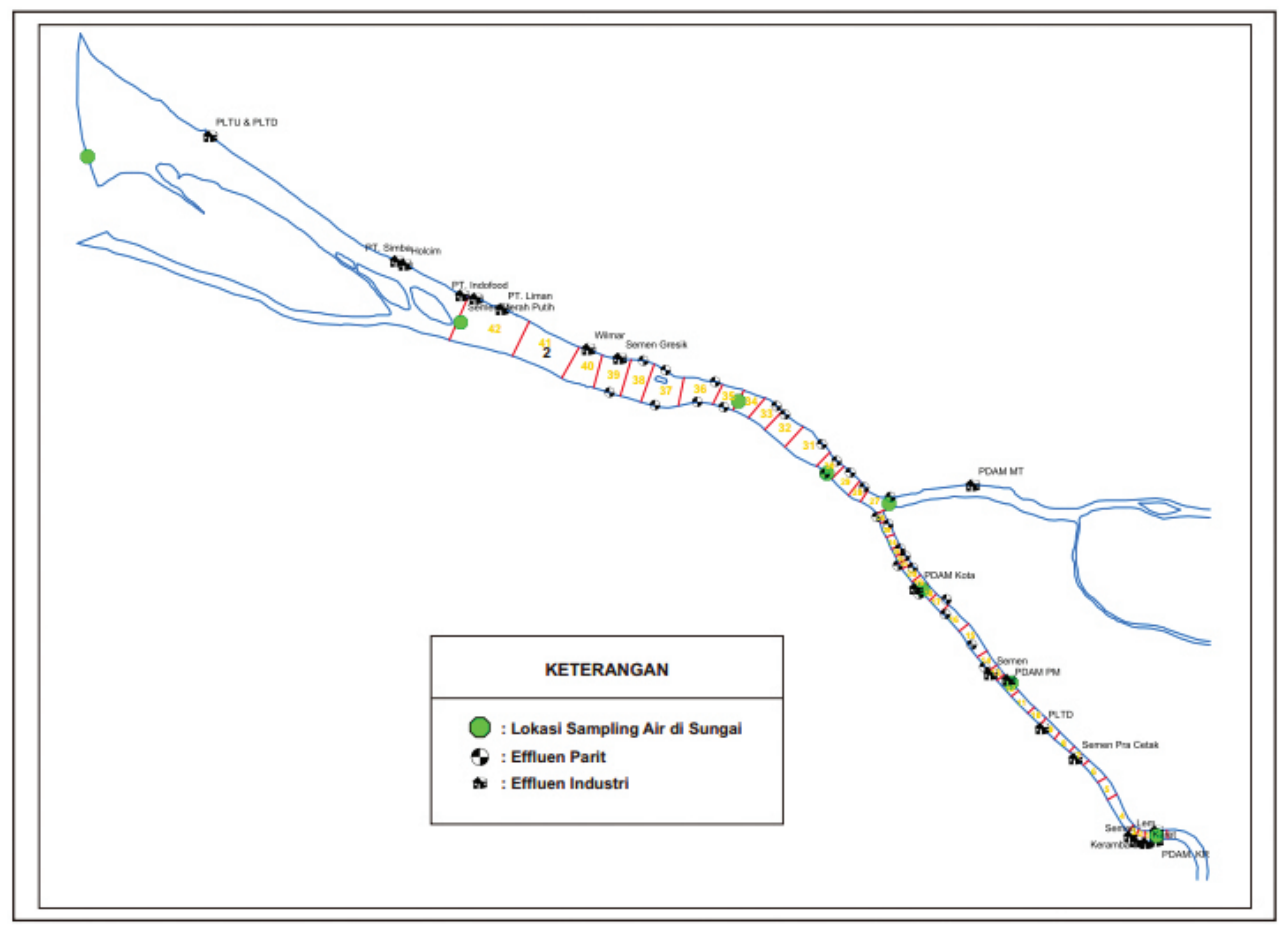

Gambar 2.

Pembagian Segmen Sungai Untuk Pemodelan 
Tabel 1

Beban Pencemaran BOD tiap Segmen

\begin{tabular}{|c|c|c|c|c|c|c|c|}
\hline \multirow[t]{2}{*}{ No } & \multirow{2}{*}{$\begin{array}{c}\text { Nama } \\
\text { Segmen }\end{array}$} & \multirow{2}{*}{$\begin{array}{c}\text { Panjang } \\
\text { (m) }\end{array}$} & \multirow[t]{2}{*}{ Lebar (m) } & \multicolumn{2}{|c|}{$\begin{array}{c}\text { Total Beban BOD } \\
\text { Kemarau (kg/hari) }\end{array}$} & \multicolumn{2}{|c|}{$\begin{array}{c}\text { Total Beban BOD Hujan } \\
\text { (kg/hari) }\end{array}$} \\
\hline & & & & Pasang & Surut & Pasang & Surut \\
\hline 1 & Segmen 1 & 532 & 246 & 230,1 & 230,1 & 195,3 & 195,3 \\
\hline 2 & Segmen 2 & 176 & 244 & $\begin{array}{l}\text { Tidak ada } \\
\text { data }\end{array}$ & $\begin{array}{l}\text { Tidak ada } \\
\text { data }\end{array}$ & $\begin{array}{l}\text { Tidak ada } \\
\text { data }\end{array}$ & $\begin{array}{l}\text { Tidak ada } \\
\text { data }\end{array}$ \\
\hline 3 & Segmen 3 & 191 & 264 & $\begin{array}{l}\text { Tidak ada } \\
\text { data }\end{array}$ & $\begin{array}{l}\text { Tidak ada } \\
\text { data }\end{array}$ & $\begin{array}{l}\text { Tidak ada } \\
\text { data }\end{array}$ & $\begin{array}{l}\text { Tidak ada } \\
\text { data }\end{array}$ \\
\hline 4 & Segmen 4 & 871 & 235 & 2,7 & 2,7 & 2,7 & 2,7 \\
\hline 5 & Segmen 5 & 489 & 227 & 154,3 & 154,3 & 154,3 & 154,3 \\
\hline 6 & Segmen 6 & 567 & 226 & $3.543,7$ & $3.543,7$ & 302,1 & 302,1 \\
\hline 7 & Segmen 7 & 477 & 204 & $\begin{array}{l}\text { Tidak ada } \\
\text { data }\end{array}$ & $\begin{array}{l}\text { Tidak ada } \\
\text { data } \\
\end{array}$ & $\begin{array}{l}\text { Tidak ada } \\
\text { data }\end{array}$ & $\begin{array}{l}\text { Tidak ada } \\
\text { data }\end{array}$ \\
\hline 8 & Segmen 8 & 482 & 183 & $3.389,5$ & $3.389,5$ & 147,8 & 147,8 \\
\hline 9 & Segmen 9 & 474 & 182 & $\begin{array}{l}\text { Tidak ada } \\
\text { data }\end{array}$ & $\begin{array}{l}\text { Tidak ada } \\
\text { data }\end{array}$ & $\begin{array}{l}\text { Tidak ada } \\
\text { data }\end{array}$ & $\begin{array}{l}\text { Tidak ada } \\
\text { data }\end{array}$ \\
\hline 10 & Segmen 10 & 396 & 223 & 4,3 & 4,3 & 4,3 & 4,3 \\
\hline 11 & Segmen 11 & 556 & 225 & 154,3 & 154,3 & 154,3 & 154,3 \\
\hline 12 & Segmen 12 & 515 & 218 & $3.389,5$ & $3.389,5$ & 147,8 & 147,8 \\
\hline 13 & Segmen 13 & 291 & 245 & $\begin{array}{l}\text { Tidak ada } \\
\text { data }\end{array}$ & $\begin{array}{l}\text { Tidak ada } \\
\text { data }\end{array}$ & $\begin{array}{l}\text { Tidak ada } \\
\text { data }\end{array}$ & $\begin{array}{l}\text { Tidak ada } \\
\text { data }\end{array}$ \\
\hline 14 & Segmen 14 & 429 & 262 & $3.389,5$ & $2.055,1$ & $1.172,4$ & 147,8 \\
\hline 15 & Segmen 15 & 772 & 227 & $1.085,8$ & $1.021,6$ & 847,6 & 55,6 \\
\hline 16 & Segmen 16 & 656 & 225 & 528,8 & 183 & 859,5 & 80,2 \\
\hline 17 & Segmen 17 & 390 & 215 & $4.187,6$ & 533,4 & 831 & 80,2 \\
\hline 18 & Segmen 18 & 322 & 238 & $1.853,9$ & 904,2 & 898,2 & 244,8 \\
\hline 19 & Segmen 19 & 276 & 236 & 250 & 250 & 250 & 250 \\
\hline 20 & Segmen 20 & 373 & 265 & 582,8 & 183 & 831,6 & 50,6 \\
\hline 21 & Segmen 21 & 144 & 215 & $4.737,1$ & $4.446,2$ & $1.800,3$ & 688,6 \\
\hline 22 & Segmen 22 & 179 & 227 & 666,5 & 409,1 & 635,4 & 65,7 \\
\hline 23 & Segmen 23 & 200 & 220 & $1.227,6$ & 337,4 & 191,5 & 26,9 \\
\hline 24 & Segmen 24 & 307 & 232 & 666,5 & 409,1 & 635,4 & 65,7 \\
\hline 25 & Segmen 25 & 362 & 206 & $2.703,8$ & $2.131,3$ & 2.082 & 891,8 \\
\hline 26 & Segmen 26 & 260 & 208 & $1.045,1$ & $3.066,1$ & 493,5 & 209,2 \\
\hline 27 & Segmen 27 & 580 & 284 & $1.113 .452,4$ & $1.126 .368,6$ & $229.667,6$ & $332.774,1$ \\
\hline 28 & Segmen 28 & 312 & 313 & $2.132,6$ & 7.076 & 843 & 100,8 \\
\hline 29 & Segmen 29 & 533 & 391 & $1.673,7$ & $7.418,5$ & 134,5 & 114,4 \\
\hline 30 & Segmen 30 & 475 & 450 & $12.200,5$ & $7.597,9$ & $4 . .548,8$ & $1.239,7$ \\
\hline 31 & Segmen 31 & 885 & 557 & 5.705 & $2.870,3$ & $1.107,7$ & 247 \\
\hline 32 & Segmen 32 & 632 & 643 & $16.487,1$ & $6.710,6$ & 836,5 & 300,1 \\
\hline
\end{tabular}




\begin{tabular}{|c|c|c|c|c|c|c|c|}
\hline \multirow[t]{2}{*}{ No } & \multirow{2}{*}{$\begin{array}{c}\text { Nama } \\
\text { Segmen }\end{array}$} & \multirow{2}{*}{$\begin{array}{c}\text { Panjang } \\
\text { (m) }\end{array}$} & \multirow[t]{2}{*}{ Lebar (m) } & \multicolumn{2}{|c|}{$\begin{array}{c}\text { Total Beban BOD } \\
\text { Kemarau (kg/hari) }\end{array}$} & \multicolumn{2}{|c|}{$\begin{array}{c}\text { Total Beban BOD Hujan } \\
\text { (kg/hari) }\end{array}$} \\
\hline & & & & Pasang & Surut & Pasang & Surut \\
\hline 33 & Segmen 33 & 505 & 550 & $2.526,7$ & $1.572,1$ & $1.043,7$ & 482,4 \\
\hline 34 & Segmen 34 & 473 & 579 & $7.817,4$ & $1.017,8$ & 442,2 & 326,2 \\
\hline 35 & Segmen 35 & 516 & 551 & $7.817,4$ & $1.017,8$ & 442,2 & 326,2 \\
\hline 36 & Segmen 36 & 889 & 629 & $22.145,2$ & $4.370,1$ & $1.392,7$ & 484,1 \\
\hline 37 & Segmen 37 & 837 & 852 & $46.397,2$ & $14.590,8$ & $3.097,1$ & 943,7 \\
\hline 38 & Segmen 38 & 529 & 928 & 14.980 .5 & 1.566 & 404,7 & 189,8 \\
\hline 39 & Segmen 39 & 682 & 781 & $67.785,8$ & $34.937,2$ & $5.425,6$ & $2.581,5$ \\
\hline 40 & Segmen 40 & 694 & 866 & 2,5 & 2,5 & 2,5 & 2,5 \\
\hline 41 & Segmen 41 & 1322 & 866 & $\begin{array}{l}\text { Tidak ada } \\
\text { data }\end{array}$ & $\begin{array}{l}\text { Tidak ada } \\
\text { data }\end{array}$ & $\begin{array}{l}\text { Tidak ada } \\
\text { data }\end{array}$ & $\begin{array}{l}\text { Tidak ada } \\
\text { data }\end{array}$ \\
\hline 42 & Segmen 42 & 1564 & 1032 & 35,3 & 35,3 & 35,3 & 35,3 \\
\hline
\end{tabular}

DebitSungai Kapuas Kecilyang digunakan untuk input model adalah $1200 \mathrm{~m}^{3}$ / detik (debit rata-rata saat pasang), $1234 \mathrm{~m}^{3} /$ detik (debit rata-rata saat surut), dan debit minimum 504 $\mathrm{m}^{3} /$ detik, sedangkan data konsentrasi BOD boundaries disajikan pada Tabel 2 .

Tabel 2

Konsentrasi BOD boundaries Sungai Kapuas Kecil

\begin{tabular}{l|l|l|l|l|l}
\hline No & \multicolumn{1}{|c|}{ Nama Segmen } & $\begin{array}{c}\text { BOD hujan- } \\
\text { pasang(mg/L) }\end{array}$ & $\begin{array}{c}\text { BOD hujan- } \\
\text { surut(mg/L) }\end{array}$ & $\begin{array}{c}\text { BOD kemarau- } \\
\text { pasang(mg/L) }\end{array}$ & $\begin{array}{c}\text { BOD kemarau- } \\
\text { surut(mg/L) }\end{array}$ \\
\hline 1 & Segmen 1 (hulu) & 3,52 & 3,52 & 8,91 & 15,14 \\
\hline 2 & Segmen 42 (hilir) & 5,28 & 7,05 & 16,51 & 9,45 \\
\hline
\end{tabular}

Dinamika karakteristik BOD di Sungai Kapuas Kecil Bagian hilir dipengaruhi pasang surut dan debit sungai. Konsentrasi BOD di sepanjang aliran bervariasi pada musim yang berbeda dengan masuknya beban pencemaran dari masing-masing effluent sumber pencemar.

Pemodelan kualitas air difokuskan untuk mensimulasikan kualitas air Sungai Kapuas Kecil dengan menjalankan model dalam dua skenario, yaitu skenario tanpa load Sungai Landak dan skenario debit minimum. Skenario yang disimulasikan bertujuan untuk mengetahui kualitas air Sungai Kapuas Kecil pada kondisi debit rata - rata maupun debit minimum pada musim kemarau dan hujan, saat pasang dan surut, dengan dan tanpa kontribusi beban pencemaran dari Sungai Landak. Hasil simulasi konsentrasi BOD untuk skenario tanpa load dari Sungai Landak dan debit minimum dapat dilihat pada Gambar 2, 3,4 , dan 5 .
Hasil simulasi secara keseluruhan pada kondisi debit rata-rata dan debit minimum pada musim hujan dan kemarau saat kondisi pasang dan surut menampilkan grafik sebaran BOD (mg/l) di sungai Kapuas Kecil yang mengalami lonjakan cukup signifikan di segmen 27 (11.000 m dari hulu boundaries) setelah beban pencemaran dari Sungai Landak masuk di segmen ini, disamping beban pencemaran dari parit-parit yang ada di sepanjang Sungai Kapuas Kecil juga memberikan kontribusi yang besar terhadap kenaikan konsentrasi BOD. Sedangkan skenario tanpa landak menampilkan sebaran konsentrasi BOD (mg/l) yang relatif lebih rendah dan rata- rata sama selama perjalanan dari hulu ke hilir walaupun mengalamai fluktuasi dan sudah melebihi mutu air kelas II berdasarkan PP 82/2001. 


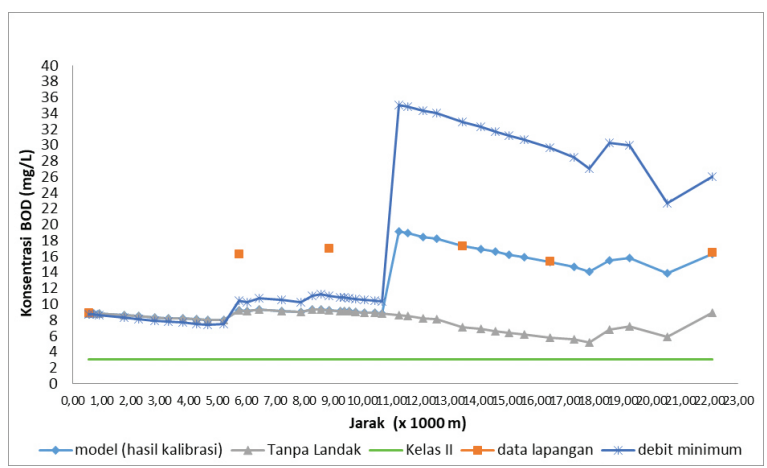

Gambar 2.

Hasil Skenario Model BOD Musim Kemarau Saat Pasang

Model sebaran BOD musim kemarau saat pasang pada beban pencemaran existing dan debit rata-rata dari arah hulu ke hilir menunjukkan pola yang semakin meningkat. Akumulasi beban pencemaran BOD mulai terjadi setelah jarak $5 \mathrm{~km}$ dari hulu boundaries dan kemudian terjadi lonjakan konsentrasi yang signifikan dengan adanya load dari segmen 27 yaitu sebesar 1.113.452,4 kg BOD/hari yang berasal dari Sungai Landak dan Parit Pekong, hingga konsentrasi BOD mencapai puncaknya 19,11 mg/l, selanjutnya konsentrasi BOD cenderung menurun hingga kearah muara. Semakin banyak beban pencemaran yang masuk ke sungai pada jarak yang berbeda-beda, maka konsentrasi BOD semakin meningkat dan waktu untuk purifikasi sungai menjadi lebih lama. Model sebaran BOD dengan skenario debit minimum menunjukkan pola yang sama, hanya konsentrasi BOD tertinggi lebih tinggi hingga $83 \%$ dari kondisi eksisting dengan konsentrasi 35,06 mg/l.setelah masuknya load dari segmen 27. Model sebaran BOD dengan skenario tanpa load dari Sungai Landak menunjukkan grafik yang landai dari hulu ke hilir dengan konsentrasi BOD tertinggi lebih rendah $50 \%$ dari kondisi eksisting (Gambar 2).

Model sebaran BOD musim kemarau saat surut pada beban pencemaran eksisting dan debit rata-rata dari arah hulu ke hilir menunjukkan pola grafik yang awalnya cenderung menurun dan kemudian berfluktuasi setelah melewati segmen 27 (11 $\mathrm{km}$ dari hulu boundaries) sampai dengan jarak $18 \mathrm{~km}$ ke arah hilir dan selanjutnya cenderung menurun kembali hingga kearah muara. Konsentrasi BOD tertinggi terjadi pada segmen 37 (5 km dari hilir boundaries) yaitu 19,4 mg/l. Model sebaran BOD dengan skenario debit minimum menunjukkan pola yang sama, hanya konsentrasi BOD lebih tinggi hingga $64 \%$ yaitu dengan konsentrasi tertinggi 31,83 $\mathrm{mg} / \mathrm{l}$. Model sebaran BOD dengan skenario tanpa load dari Sungai Landak menunjukkan pola yang hampir sama, hanya konsentrasi BOD lebih rendah $20 \%$ dari kondisi eksisting dengan konsentrasi tertinggi 16,08 mg/l yang juga terjadi di segmen yang sama yaitu segmen 37 (Gambar 3).

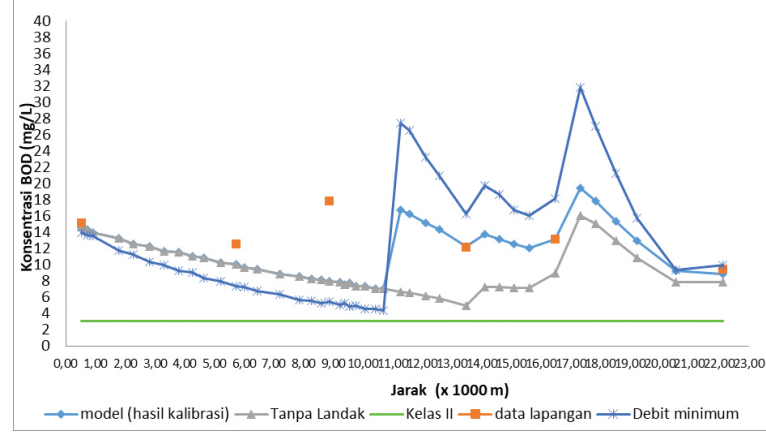

Gambar 3.

Hasil Skenario Model BOD Musim Kemarau Saat Surut

Model sebaran BOD pada musim hujan saat surut dengan semua skenario yang dijalankan yaitu pada debit rata-rata, debit minimum, dan tanpa masukan dari load sungai Landak dari arah hulu ke hilir menunjukkan pola grafik yang sama (Gambar 4). Pada skenario debit rata-rata dan debit minimum terjadi lonjakan dengan masuknya load dari Sungai Landak pada jarak $11 \mathrm{~km}$ dari hulu boundaries, selanjutnya cenderung menurun sampai dengan jarak 16,5 $\mathrm{km}$ dan kembali terjadi lonjakan pada jarak $19 \mathrm{~km}$ ke arah hilir untuk selanjutnya kembali menurun hingga kearah muara. Pada model sebaran BOD dengan skenario tanpa load dari Sungai Landak tidak terjadi lonjakan konsentrasi pada jarak 11 $\mathrm{km}$ dari hulu boundaries dan konsentasi yang lebih rendah dari kondisi eksisting. 


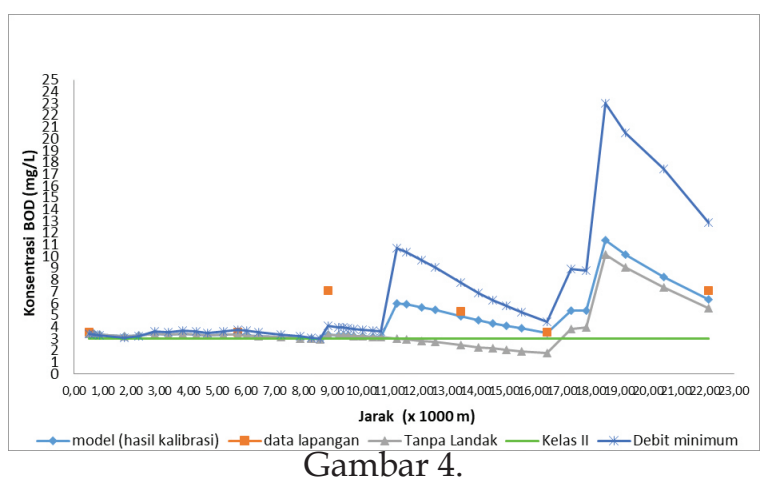

Hasil Skenario Model BOD Musim Hujan Saat Surut

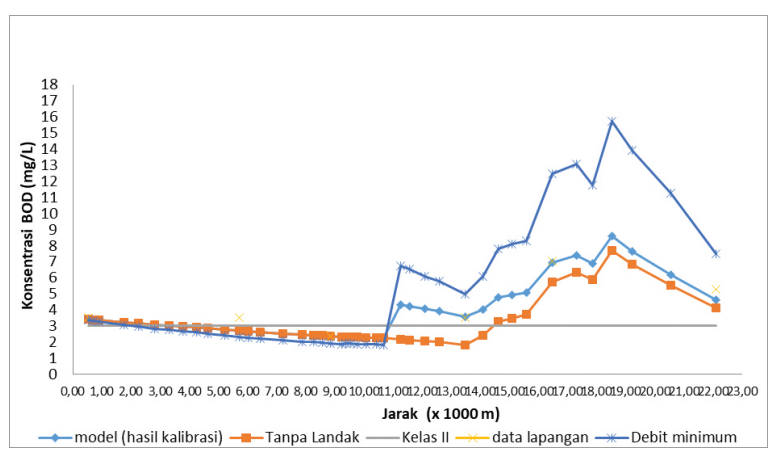

Gambar 5.

Hasil Skenario Model BOD Musim Hujan Saat Pasang

Model sebaran BOD pada musim hujan saat pasang dengan semua skenario yang dijalankan yaitu pada debit rata-rata, debit minimum dan tanpa masukan dari load Sungai Landak (Gambar 5) menunjukkan pola yang hampir sama, pada awalnya konsentrasi BOD dari arah hulu menunjukkan pola yang relatif menurun dan masih memenuhi baku mutu air kelas II PP 82/2001, tetapi kemudian terjadi lonjakan yang signifikan dengan masuknya load dari Sungai Landak pada jarak $11 \mathrm{~km}$ dari hulu boundaries dan terus meningkat sampai dengan jarak $19 \mathrm{~km}$ ke arah hilir, kemudian selanjutnya konsentrasi BOD cenderung menurun hingga ke arah muara. Model sebaran BOD dengan skenario debit minimum konsentrasi BOD tertinggi lebih tinggi $84 \%$ dari kondisi eksisting, sedangkan model sebaran BOD dengan skenario tanpa load dari Sungai Landak konsentrasi BOD tertinggi hanya $10 \%$ lebih rendah dari kondisi eksisting.
Secara umum dari hasil simulasi dengan semua skenario yang dijalankan menunjukkan load dari sungai landak secara signifikan sangat berpengaruh pada beban pencemaran di Sungai Kapuas Kecil. Konsentrasi BOD mulai meningkat dari titik pertemuan dengan Sungai Landak (11 km dari hulu boundaries) dan terus meningkat sampai ke puncaknya pada jarak $18-19 \mathrm{~km}$ dari hulu boundaries $(5 \mathrm{~km}$ sebelum menuju hilir) selanjutnya setelah itu kembali menurun sampai ke hilir. Hal ini disebabkan karena daerah hilir dekat muara sehingga ada pengaruh volume air laut dan terjadi pencampuran (mixing) dan pengenceran. Selain itu arus air cenderung memiliki arah bolak-balik sesuai dengan pasut yang terjadi. Pola sebaran konsentrasi BOD secara signifikan dipengaruhi oleh pola arus yang terjadi (Sukarno \& Yusuf, 2013). Sirkulasi aliran di estuari dipengaruhi oleh sifat-sifat morfologi estuari, pasang surut, dan debit aliran dari hulu (debit sungai). Sirkulasi aliran tersebut meliputi penjalaran gelombang pasang surut, pencampuran antara air tawar dan air asin, gerak sedimen, polutan (biologis, kimiawi, dan fisis), dan sebagainya (Triatmodjo, 1999). Hasil penelitian Pin Shu, 2004 juga menunjukkan bahwa dispersi oleh gelombang pasang berperan penting pada transportasi polutan di muara.

\section{SIMPULAN}

Hasil penelitian menunjukkan bahwa buangan domestik dan nondomestik perkotaan yang masuk ke sungai sangat dominan mempengaruhi kualitas air sungai. Konsentrasi BOD lebih tinggi pada saat musim kemarau pasang dan surut dibandingkan pada saat musim hujan pasang dan surut.

Hasil simulasi distribusi spasial dengan semua skenario yang dijalankan menunjukkan bahwa akumulasi beban pencemaran BOD mulai terjadi setelah jarak $5 \mathrm{~km}$ dari hulu boundaries dan kemudian terjadi lonjakan konsentrasi yang signifikan dengan adanya load di segmen 27 yang berasal dari Sungai Landak dan Parit Pekong. Konsentrasi BOD selanjutnya cenderung berfluktuasi dan kembali meningkat sampai pada jarak $5 \mathrm{~km}$ sebelum menuju hilir, dan setelah itu terus 
menurun sampai ke hilir. Hal ini disebabkan karena daerah hilir dekat muara sehingga ada pengaruh volume air laut dan arus air yang cenderung memiliki arah bolak-balik sesuai dengan pasut yang terjadi sehingga terjadi pengenceran dan pencampuran.

\section{DAFTAR PUSTAKA}

Ambrose, R.B. dan Wool, T.A. 2009. WASP7 Stream Transport-Model Theory and User's: Supplement to Water Analysis Simulation Program (WASP) User Documentation, Environmental Research Laboratory. Washington: DC. U.S. EPA.

Dishiros Angkatan Laut Indonesia. 2014. Daftar Pasang Surut Indonesia. Ancol. Jakarta: Ancol.

Dirjen Pengendalian Pencemaran dan Kerusakan Lingkungan KLHK. 2016. Laporan Inventarisasi dan Identifikasi Sumber Pencemar Berbasis Daerah Aliran Sungai (DAS), Kajian Penetapan Kelas Air dan Kajian Penetapan Alokasi Beban Pencemaran Sungai Kapuas. Jakarta.

Hindriani, H., Sapei, A., Suprihatin dan Machfud. 2013. Identifikasi Daya Tampung Beban Pencemaran Sungai Ciujung dengan Model WASP dan Strategi Pengendaliannya, J. Bumi Lestari. 13(2): 275-287.

Ji, Z. G. 2012. River Fate and Transport, chapter in J.S. Gulliver (ed.), Transport and Fate of Chemicals in the Environment. New York: Springer Science Business Media.

Kuo, J. T., Huang, C. H., dan Lung, W. S. 2000, Water Quality Modeling and Risk Analysis of the Chi-Shui River, Jurnal Water Resources. copyright ASCE 2004.

Lai, Y.C., Tu, Y.T., Yang, C.P. Surampalli, R.Y. dan Kao, C.M.. 2013. Development of a Water Quality Modeling System for River Pollution Index and Suspended
Solid Loading Evaluation. Journal of Hydrology. 478: 89-101.

Liang, D., Wang, X., Evans, B., Falconer,R.A.. 2013. Study on Nutrient Distribution and Interaction with Sediment in a Macro-Tidal Estuary. Advances in Water Resources 52: 207-220.

Peraturan Pemerintah No. 82 Tahun 2001 Pengelolaan Kualitas Air dan Pengendalian Pencemaran Air. Jakarta.

Pin Shu, W. 2004. The Use Of A Water Quality Model To Evaluate The Impacts Of Combined Sewer Overflows On The Lower Hudson River. Dissertation. New Jersey Institute of Technology.

Pusat Pengelolaan Ekoregion Kalimantan Kementrian Lingkungan Hidup. 2011. Laporan Status Lingkungan Hidup Ekoregion Kalimantan. Jakarta.

Sukarno, M. dan Yusuf, M., 2013, Kondisi Hidrodinamika dan Pengaruhnya terhadap Sebaran Parameter FisikaKimia Perairan Laut dari Muara Sungai Porong, Sidoarjo. Buletin Oseanografi Marina. 4(2): 1-6.

Triatmodjo, B. 1999. Teknik Pantai. Beta Offset. Yogyakarta.

U.S. EPA (United States Environmental Protection Agency).2009. Water Quality Analysis Simulation Program (WASP) Version 7.4. Development National Exposure Research Laboratory Ecosystem Research Division. Athens. GA.

Wool, T.A., Ambrose, R.B., Martin J.L. dan Corner. E.A.. 2001. Water Quality Analysis Simulation Program (WASP) version 6.0 User's Manual. Athens: GA. U.S. EPA. 